\title{
Worldwide patterns of ischemic heart disease mortality from 1980 to 2010
}

\author{
Cláudia Gouvinhas ${ }^{1}$, Milton Severo ${ }^{1}$, Ana Azevedo ${ }^{1}$, Nuno Lunet $*, 1$ \\ Department of Clinical Epidemiology, Predictive Medicine and Public Health, University of Porto Medical School, Portugal \\ Institute of Public Health, University of Porto (ISPUP), Portugal
}

\section{A R T I C L E I N F O}

Article history:

Received 13 December 2012

Accepted 1 November 2013

Available online 13 November 2013

\section{Keywords:}

Myocardial ischemia

Mortality

Epidemiology

Cluster analysis

\begin{abstract}
A B S T R A C T
Background: The trends in the IHD mortality rates vary widely across countries, reflecting the heterogeneity in the variation of the exposure to the main risk factors and in the access to different management strategies among settings. We aimed to identify model-based patterns in the time trends in IHD mortality in 50 countries from the five continents, between 1980 and 2010.

Methods and results: Mixed models were used to identify time trends in age-standardized mortality rates (ASMR) (age group 35+ years; world standard population), all including random terms for intercept, slope, quadratic and cubic. Model-based clustering was used to identify the patterns.

We identified five main patterns of IHD mortality trends in the last three decades, similar for men and women. Pattern 1 had the highest ASMR and pattern 2 exhibited the most pronounced decrease in ASMR during the entire study period. Pattern 3 was characterized by an initial increase in ASMR, followed by a sharp decline. Countries in pattern 4 had the lowest ASMR throughout the study period. It was further divided into patterns $4 \mathrm{a}$ (consistent decrease in ASMR throughout the period of analysis) and $4 \mathrm{~b}$ (less pronounced declines and highest rates observed mostly between 1996 and 2004). There was no correspondence between the geographic or economical grouping of the analyzed countries and the patterns found in this study.

Conclusions: Our study yielded a new framework for the description, interpretation and prediction of IHD mortality trends worldwide.
\end{abstract}

(c) 2013 Elsevier Ireland Ltd. All rights reserved.

\section{Introduction}

Worldwide, cardiovascular diseases (CVD) were responsible for 17.3 million deaths in 2008 , corresponding to $32 \%$ of all deaths in women and $27 \%$ in men. Ischemic heart disease (IHD) and cerebrovascular diseases are responsible for approximately two thirds of the CVD deaths [1], with IHD accounting for 7.3 million deaths yearly. Approximately four fifths of these occur in low and middle income countries (LMIC) [2] and IHD remains the leading cause of death in high income settings [1,3], despite the downward trends observed in the last decades [4].

This decline results primarily from changes in exposure to major risk factors, including decreases in tobacco consumption $[5,6]$ and physical inactivity $[7,8]$, lower blood pressure $[9,10]$ and serum cholesterol $[10,11]$ in the general population, and a better control of dyslipidaemia [8] and hypertension [12-15], as well as from the increasing access to

\footnotetext{
* Corresponding author at: Departamento de Epidemiologia Clínica, Medicina Preditiva e Saúde Pública, Faculdade de Medicina da Universidade do Porto, Al. Prof. Hernâni Monteiro, 4200-319 Porto, Portugal. Tel.: + 35122551 3652; fax: + 351225513653.

E-mail address: nlunet@med.up.pt (N. Lunet).

1 This author takes responsibility for all aspects of the reliability and freedom from bias of the data presented and their discussed interpretation.
}

earlier and more effective management of acute coronary syndromes $[16,17]$ and uptake of long-term secondary prevention $[14,18]$.

The trends in the IHD mortality rates vary widely across countries, reflecting the heterogeneity in the variation of the exposure to the main risk factors and in the access to different management strategies among settings. Previous attempts to describe worldwide patterns of IHD mortality trends relied on grouping the countries mostly based on geographical criteria or socio-economic characteristics $[19,20]$. However, model-based clustering may allow the definition of more homogeneous groups of countries, accounting for the mortality rates at the onset of the observation period, as well as the magnitude and slope of its variation, with no a priori constraints.

This study aimed to identify patterns of time trends in IHD mortality across countries, using a model-based approach.

\section{Methods}

All European countries, high-income non-European countries and the leading emerging economies jointly referred to as BRICS, as defined by the United Nations (UN) [21], with available data were eligible for the present study.

We abstracted death certification data from the World Health Organization (WHO) database [22], for the period between 1980 (or the first calendar year with available data since 1980) and 2010 (or the most recent data available) for each country. Countries with no data available in electronic support (India) or having data available for less than 
10 consecutive or alternate calendar years (Bosnia and Herzegovina, Cyprus and Montenegro) were excluded. From China we considered two sets of data: estimates for the mainland country, based on samples of less than $10 \%$ of the population, and specific data from the Hong Kong Special Administrative Region (SAR).

Between 1980 and 2010 three different revisions of the International Classification of Diseases (ICD) were used to classify the causes of death [23-25]. We extracted the number of deaths due to IHD, corresponding to the codes A083 (ICD-8), B27 (ICD-9) or I20-I25 (ICD-10) [22]. The deaths with no information regarding sex were equally distributed by men and women.

Mid-year estimates of the resident population were obtained from the 2010 revision of UN World Prospects Population [21], even when mortality data referred to less than $90 \%$ of the country population. The latter applies to Albania (70.8\%), Brazil (79.7\%), Republic of Moldova (83.2\%), Serbia (83.1\%), South Africa (76.9\%) and The Former Yugoslav Republic (TFYR) of Macedonia (89.2\%). The population estimates for China were obtained from the WHO database [22].

Sex-specific and age-standardized mortality rates (ASMR) were computed through the direct method, using the world standard population [26] as reference. These data were available for 38 European, and eight non-European countries, namely Australia, Canada, Japan, New Zealand and United States of America (USA), Brazil, China, and South Africa (Fig. 1). Model-based patterns were defined using the ASMR referring to the ages $35+$, separately for men and women.

Mixed models, including random terms by country for the intercept, slope, quadratic and cubic terms, were used to describe the time trends in the ASMR. The rates in the years with missing data, between 1980 and 2010, were estimated by these models. Both the observed mortality rates and the model predictions are presented in Appendices 1 and 2. We excluded from further analyses the data referring to Belarus, Republic of Moldova, Russia and Ukraine, because for these countries the models yielded coefficients over three times the interquartile range above or below the median of all countries, for the quadratic and/or cubic terms, for men and/or women (Fig. 1). Croatia was also excluded because no reliable estimation of ASMR in the years with missing data could be obtained with these relatively simple models (Fig. 1 and Appendices 1 and 2).

Model-based clustering was used to identify the patterns in the IHD mortality trends, using the ASMR estimated for the period 1980-2010. In this method, the clusters are considered to be ellipsoidal, centered at the means, and the covariances determine their other geometric features. Characteristics (orientation, volume and shape) of distributions are estimated from the data, and can be allowed to vary between clusters, or constrained to be the same for all clusters. The most appropriate models were considered those allowing for the most homogeneous grouping of the countries regarding their patterns of variation, as assessed by visual inspection of the country-specific trends, selected among those with the lowest Bayesian Information Criterion (BIC) (Appendix 3).

The reliability of the model-based clustering was evaluated by tenfold cross validation [27]. The sample was divided in ten partitions, and each of the subsets of nine out of ten partitions was used to fit a different model. The agreement between the predictions from these models and those from the model obtained with the complete dataset was calculated; the overall kappa coefficient was estimated by the mean of the coefficients referring to the agreement between each of the ten subset models and the full model.

The clusters corresponding to homogenous groups of countries regarding the trends in ASMR were further divided according to the gross national income, Atlas method, per capita (GNI) [28] in 1995 (the midpoint of the period under analysis) to increase the homogeneity of the patterns. For Serbia and Hong Kong SAR we used the GNI in 1999, for Estonia, Ireland and Czech Republic we used de GNI in 2002, as these were the first years with available data for these countries.

Data analyses were conducted using the software $R 2.14 .1$

\section{Results}

We identified four patterns of variation in IHD mortality, hereafter referred to as patterns 1 to 4 (Figs. 1 and 2). The reliability of the model-based clustering was very good, as shown by the agreement between each of the ten subset models and the full model (men: kappa $=0.83$; women: kappa $=0.94$ ).

Among men, despite the heterogeneous GNI values across the countries included in each pattern, all those included in pattern 2 were above the World Bank threshold to define upper middle income countries (UMIC) (3035 USD in 1995). Pattern 4 included 11 high income countries (HIC), two UMIC, two low income countries (LIC) and two LMIC



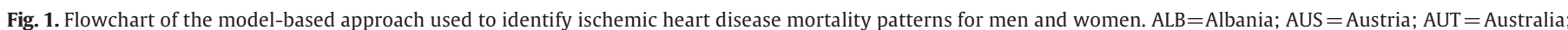

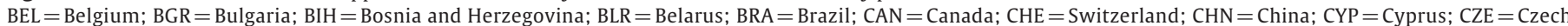

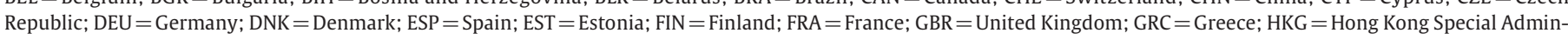

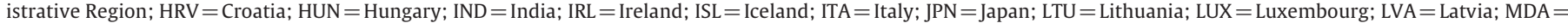



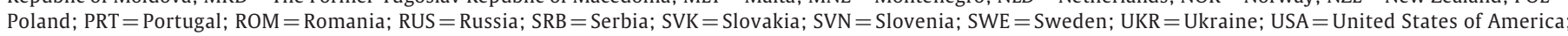
$\mathrm{ZAF}=$ South Africa. 
Men



Women

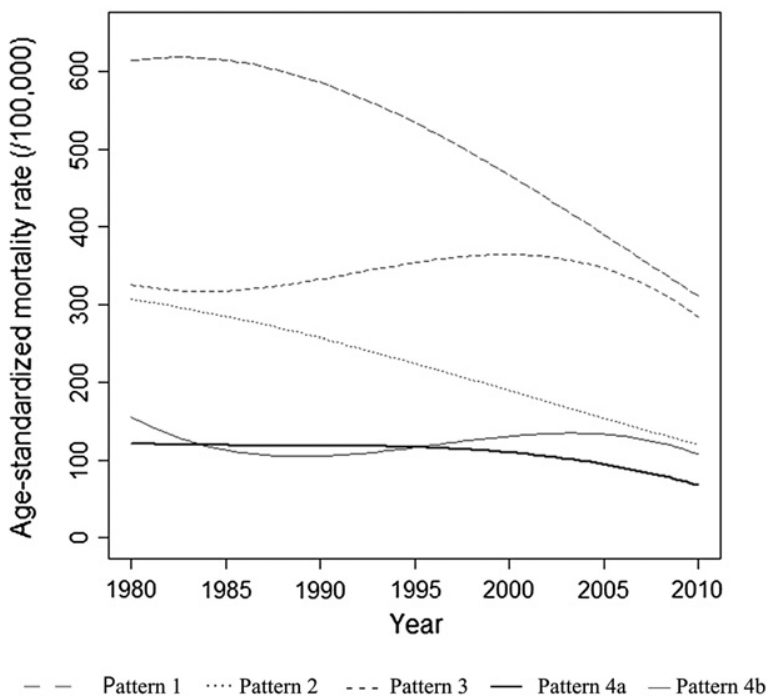

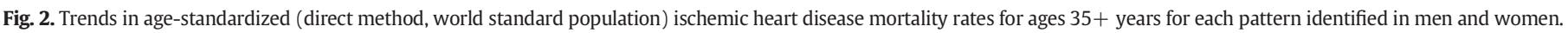

and we divided it into patterns 4a, including the 13 UMIC or HIC, and 4b, including four LIC or LMIC. Pattern 1 had two LMIC and only one UMIC while pattern 3 included six UMIC or HIC and only two LMIC; these patterns were not further divided (Fig. 3). Among women, there was a similar relation between the patterns and the countries' GNI; pattern 4 was also divided into 4 a including 16 UMIC or HIC and $4 \mathrm{~b}$ including two LIC and two LMIC. Pattern 1 included two LMIC and one UMIC and patterns 2 and 3 included only one LMIC; these patterns were not further divided.

Pattern 1 is characterized by the highest ASMR throughout the period of analysis, with a pronounced decline only in its second half, both in men and women (Fig. 2). It includes only northern European countries (Figs. 2 and 4).

Pattern 2 includes essentially UMIC and HIC, from different regions. It is characterized by high ASMR in 1980, though nearly half the observed for pattern 1 , that declined steeply throughout the whole period and are among the lowest in 2010 (Figs. 2 and 4).

Among men, pattern 3 includes countries from eastern, southern and western Europe, while in women it included only eastern European countries. The highest ASMR were observed mostly between 1999 and 2005, and in 2010 were similar to the observed in pattern 1 (Table 1 ).

Most of the countries included in pattern 4a, as well as its general characteristics, were the same among men and women. It includes mostly southern and western European countries, as well as Japan, Hong Kong SAR, South Africa and Brazil. The ASMR were among the lowest and declined throughout the whole period under analysis, though more steeply in its second half. Pattern $4 \mathrm{~b}$ includes only southern European and China (mainland); the rates are not substantially different from the observed for pattern 4a, though the decline is less pronounced and the highest rates are observed mostly between 1996 and 2004 (Fig. 2 and Table 1).

\section{Discussion}

We identified five main patterns of IHD mortality trends in the last three decades. The clusters defined with this model-based approach are substantially different from those obtained using only geographical or economic criteria, and these results provide a new framework for the


Fig. 3. Gross national income (Atlas method) per capita, by pattern, in men and women. 

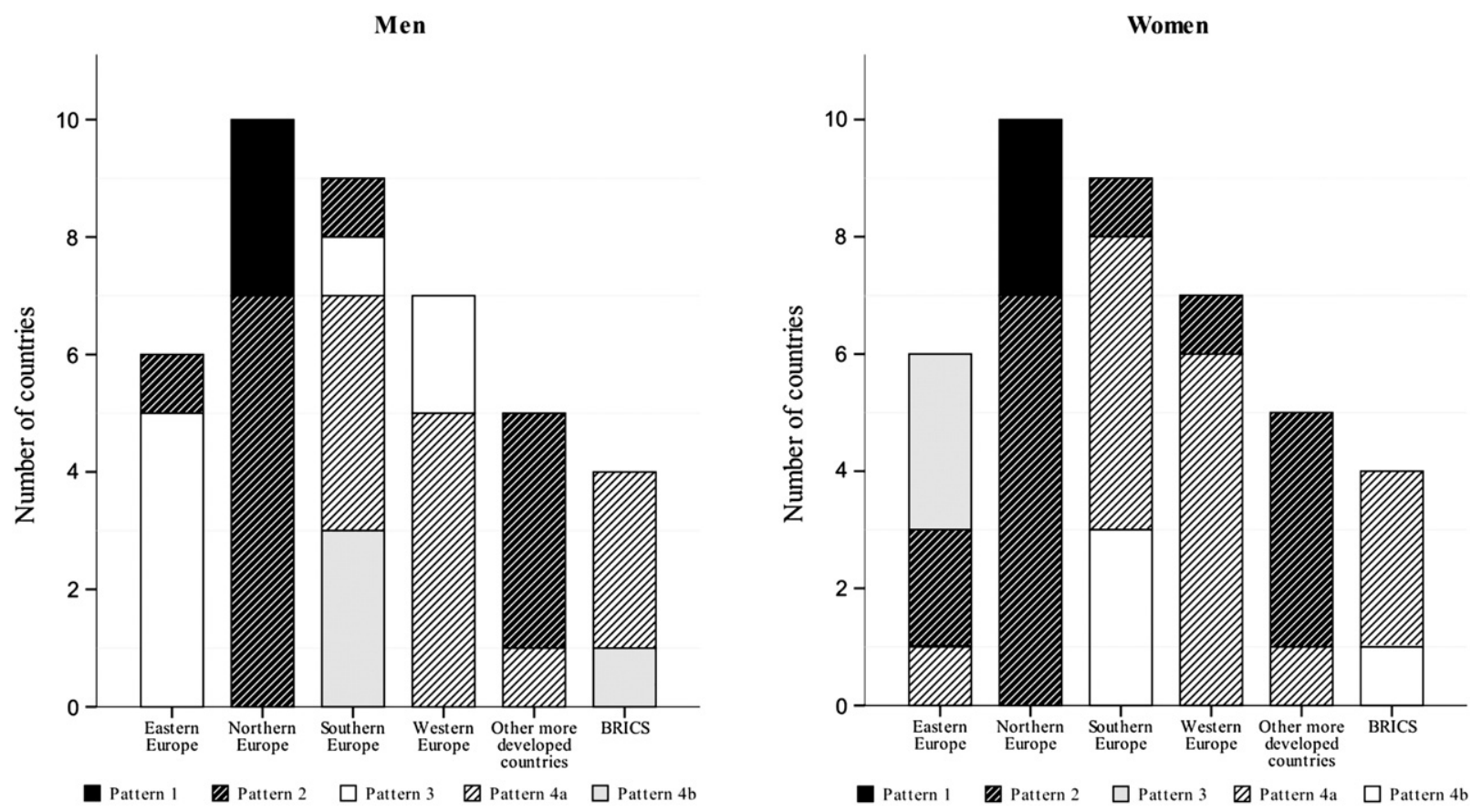

Fig. 4. Countries included in each pattern, by geographic region, in men and women.

description, interpretation and prediction of the IHD mortality trends worldwide.

The interpretation of the trends in IHD mortality requires the understanding of the variation in the main determinants of its incidence and survival. Models [33] developed to explain the changes in IHD mortality rates observed in specific settings, through the use of standardized methods to account for the impact of variables thought to influence coronary heart disease mortality (including exposure to the main risk factors, and uptake of treatment, combined with demographic information) may provide valuable data to interpret our findings.

For seven countries of pattern 2, namely England and Wales, Finland, Iceland, Ireland, New Zealand, Sweden, and USA, we obtained data based on the framework of analysis of the IMPACT model [7,18,34-38]. Despite the heterogeneity regarding the periods of analysis (mostly between the 1980 s and the first years after 2000, except for 1982-1993 in New Zealand and 1994-2002 in Sweden), the reductions in the exposure to the major risk factors explain approximately half of the decline in IHD mortality in most of these settings, though the estimate for Iceland was $73 \%$ and ranged between $44 \%$ and $58 \%$ in the remaining countries. The contribution of the variation in the exposure to specific risk factors was much more heterogeneous: England and Wales had the highest percentage of reduction attributable to smoking (48\%) and the lowest attributable to serum total cholesterol levels $(10 \%)$, while the inverse was observed for Sweden (the percentages were 9\% and 39\%, respectively); the estimates for blood pressure ranged from $6 \%$ in Ireland to $22 \%$ Iceland. No substantial gender differences were observed in risk factor trends, which is in accordance with our observation of similar patterns of IHD mortality trends in men and women.

Medical and surgical treatments explained from 23\% to $49 \%$ of the decrease in IHD mortality in Finland and Ireland, respectively. Despite the large differences between countries regarding the contribution of specific treatments, secondary prevention had the largest contribution to the decrease in most settings, though ranging from 6\% in Finland to $18 \%$ in Ireland, followed by the treatment for heart failure (range: $2 \%-$ $14 \%$, in Finland and Ireland, respectively) and the initial treatment of acute myocardial infarction (range: 4\%-12\%, in Finland and New Zealand, respectively). These results show that despite the homogeneity of the patterns of variation in IHD mortality, the factors that determine such trends seem to vary substantially across settings, showing that similar effects on the mortality rates may be achieved through different paths, supporting the potential for further reduction in the burden of IHD through more comprehensive actions for its prevention and control. Published reports providing IMPACT model estimates were available also for Italy and Spain (pattern 4a), for the periods 1980-2000 and 1988 to 2005 , respectively $[39,40]$. The decrease in mortality attributable to risk factors (55\% in Italy, 50\% in Spain) was mainly due to the decrease in serum total cholesterol levels (31\% in Spain) and blood pressure $(25 \%$ in Italy). The variation in the exposure to smoking had a substantially different impact in Spain (16\%) and Italy (4\%). Regarding the impact of medical and surgical treatments, the estimates were more similar and secondary prevention still had the largest contribution to the decrease (16\% in Italy and 10\% in Spain).

In countries of pattern 1, the high IHD mortality is consistent with the also high levels of exposure to tobacco smoking and use of alcohol $[41,42]$, as well as poor control of hypertension, despite favorable changes in hypertension awareness and treatment [43]. Pattern 3 includes countries that experienced socioeconomic changes during the transition to a market economy in the 1990s; this applies to countries such as Poland, Romania or Hungary, after the communist era $[44,45]$. Countries with increasing trends of smoking, obesity, diabetes [46] and systolic blood pressure [11], are included in the pattern 4b, which is also compatible with the trends observed.

Although some countries depict a variation in mortality rates that may be compatible with more than one pattern, the model-based clustering yielded essentially the same results when different subsets of the eligible countries were considered, strengthening the robustness of our findings. Belarus, Republic of Moldova, Russia and Ukraine were excluded from our analysis because their model coefficients were substantially different from those of all the other countries. This, however, reflects the fact that they all have irregular IHD trends (Appendices 1 and 2), which may be interpreted as a pattern itself, characterized by the highest IHD ASMR, throughout most of the period under analysis, as well as by an initial decrease in the IHD ASMR, until 1990, followed by an increase which is recently becoming less steep. The major socioeconomic 
Table 1

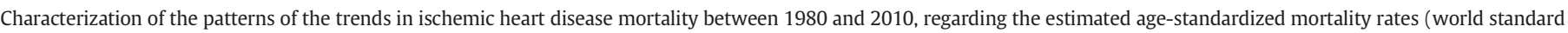

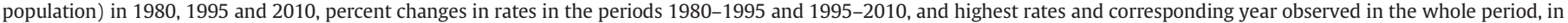
the age-group $35+$ years, in men and women.

\begin{tabular}{|c|c|c|c|c|c|}
\hline & \multicolumn{5}{|c|}{$\begin{array}{c}\text { Median } \\
\text { (P25 to P75) }\end{array}$} \\
\hline & Pattern 1 & Pattern 2 & Pattern 3 & Pattern 4a & Pattern 4b \\
\hline \multicolumn{6}{|l|}{ Men } \\
\hline \multicolumn{6}{|l|}{ ASMR* } \\
\hline 1980 & $\begin{array}{l}1046.5 \\
\text { (876.1 to } 1069.5)\end{array}$ & $\begin{array}{l}675.9 \\
(639.3 \text { to } 707.9)\end{array}$ & $\begin{array}{l}407.9 \\
(299.0 \text { to } 548.1)\end{array}$ & $\begin{array}{l}252.7 \\
(207.5 \text { to } 338.1)\end{array}$ & $\begin{array}{l}296.2 \\
(178.3 \text { to } 337.3)\end{array}$ \\
\hline 1995 & $\begin{array}{l}967.9 \\
(959.7 \text { to } 988.7)\end{array}$ & $\begin{array}{l}399.1 \\
\text { (388.7 to } 486.6 \text { ) }\end{array}$ & $\begin{array}{l}444.1 \\
(356.3 \text { to } 578.2 \text { ) }\end{array}$ & $\begin{array}{l}202.2 \\
(167.4 \text { to } 253.5)\end{array}$ & $\begin{array}{l}219.6 \\
(160.7 \text { to } 275.7)\end{array}$ \\
\hline 2010 & $\begin{array}{l}596.4 \\
\text { ( } 474.3 \text { to } 720.8 \text { ) }\end{array}$ & $\begin{array}{l}216.6 \\
\text { ( } 176.6 \text { to } 248.5 \text { ) }\end{array}$ & $\begin{array}{l}249.2 \\
\text { (196.3 to } 465.8 \text { ) }\end{array}$ & $\begin{array}{l}128.1 \\
\text { (98.1 to } 142.3 \text { ) }\end{array}$ & $\begin{array}{l}216.0 \\
(150.6 \text { to } 222.8)\end{array}$ \\
\hline \multicolumn{6}{|l|}{ Variation in ASMR (\%)† } \\
\hline 1980-1995 & $\begin{array}{l}-7.6 \\
(-8.3 \text { to } 10.5)\end{array}$ & $\begin{array}{l}-37.8 \\
(-42.7 \text { to }-30.0)\end{array}$ & $\begin{array}{l}9.5 \\
(-10.2 \text { to } 26.5)\end{array}$ & $\begin{array}{l}-25.9 \\
(-32.9 \text { to }-15.0)\end{array}$ & $\begin{array}{l}-19.5 \\
(-28.9 \text { to }-1.1)\end{array}$ \\
\hline $1995-2010$ & $\begin{array}{l}-37.8 \\
(-52.0 \text { to }-25.5)\end{array}$ & $\begin{array}{l}-46.6 \\
(-55.4 \text { to }-42.1)\end{array}$ & $\begin{array}{l}-43.2 \\
(-52.6 \text { to }-19.1)\end{array}$ & $\begin{array}{l}-39.5 \\
(-46.6 \text { to }-29.4)\end{array}$ & $\begin{array}{l}-14.1 \\
(-25.9 \text { to } 1.2)\end{array}$ \\
\hline \multicolumn{6}{|l|}{ ASMR $\ddagger$} \\
\hline Highest value observed & $\begin{array}{l}1158.7 \\
\text { (1061.3 to } 1249.4 \text { ) }\end{array}$ & $\begin{array}{l}689.4 \\
(636.4 \text { to } 712.7)\end{array}$ & $\begin{array}{l}494.2 \\
\text { (400.1 to } 616.3 \text { ) }\end{array}$ & $\begin{array}{l}253.9 \\
\text { (206.4 to 333.9) }\end{array}$ & $\begin{array}{l}260.8 \\
\text { (196.9 to 298.1) }\end{array}$ \\
\hline Year of highest value & $\begin{array}{l}1993 \\
\text { (1985 to } 1994)\end{array}$ & $\begin{array}{l}1980 \\
(1980 \text { to } 1983)\end{array}$ & $\begin{array}{l}1994 \\
\text { (1991 to } 1998)\end{array}$ & $\begin{array}{l}1980 \\
(1980 \text { to } 1985)\end{array}$ & $\begin{array}{l}1998 \\
\text { (1996 to 2004) }\end{array}$ \\
\hline \multicolumn{6}{|l|}{ Women } \\
\hline \multicolumn{6}{|l|}{ ASMR* } \\
\hline 1980 & $\begin{array}{l}613.6 \\
(597.1 \text { to } 631.2)\end{array}$ & $\begin{array}{l}309.7 \\
(270.8 \text { to } 342.1)\end{array}$ & $\begin{array}{l}302.7 \\
(210.4 \text { to } 465.4)\end{array}$ & $\begin{array}{l}120.6 \\
\text { (91.4 to } 161.3)\end{array}$ & $\begin{array}{l}158.9 \\
(121.8 \text { to } 187.7)\end{array}$ \\
\hline 1995 & $\begin{array}{l}541.5 \\
\text { ( } 481.8 \text { to } 579.8 \text { ) }\end{array}$ & $\begin{array}{l}224.7 \\
\text { (193.9 to } 255.2 \text { ) }\end{array}$ & $\begin{array}{l}334.1 \\
\text { (323.2 to } 404.1 \text { ) }\end{array}$ & $\begin{array}{l}106.4 \\
\text { (85.9 to } 135.2)\end{array}$ & $\begin{array}{l}121.8 \\
\text { (93.4 to } 134.6 \text { ) }\end{array}$ \\
\hline 2010 & $\begin{array}{l}287.4 \\
\text { (256.1 to } 289.3 \text { ) }\end{array}$ & $\begin{array}{l}117.1 \\
\text { (98.2 to } 141.1 \text { ) }\end{array}$ & $\begin{array}{l}278.3 \\
(230.3 \text { to } 342.7)\end{array}$ & $\begin{array}{l}62.1 \\
(48.6 \text { to } 87.9)\end{array}$ & $\begin{array}{l}108.8 \\
\text { (91.1 to 123.9) }\end{array}$ \\
\hline \multicolumn{6}{|l|}{ Variation in ASMR (\%)† } \\
\hline 1980-1995 & $\begin{array}{l}-14.2 \\
(-21.5 \text { to }-2.9)\end{array}$ & $\begin{array}{l}-32.1 \\
(-34.7 \text { to }-19.7)\end{array}$ & $\begin{array}{l}6.8 \\
(-13.2 \text { to } 58.8)\end{array}$ & $\begin{array}{l}-16.0 \\
(-25.3 \text { to } 9.1)\end{array}$ & $\begin{array}{l}-19.3 \\
(-44.4 \text { to }-3.9)\end{array}$ \\
\hline $1995-2010$ & $\begin{array}{l}-40.4 \\
(-52.8 \text { to }-32.9)\end{array}$ & $\begin{array}{l}-48.3 \\
(-55.2 \text { to }-39.6)\end{array}$ & $\begin{array}{l}-15.2 \\
(-31.1 \text { to } 13.9)\end{array}$ & $\begin{array}{l}-43.4 \\
(-45.7 \text { to }-32.7)\end{array}$ & $\begin{array}{l}-13.9 \\
(-25.4 \text { to } 27.3)\end{array}$ \\
\hline \multicolumn{6}{|l|}{ ASMR $\ddagger$} \\
\hline Highest value observed & $\begin{array}{l}671.3 \\
(666.6 \text { to } 675.9)\end{array}$ & $\begin{array}{l}320.6 \\
(300.5 \text { to } 347.2)\end{array}$ & $\begin{array}{l}373.6 \\
(354.7 \text { to } 484.5)\end{array}$ & $\begin{array}{l}135.3 \\
\text { (100.1 to } 179.2 \text { ) }\end{array}$ & $\begin{array}{l}152.7 \\
(121.2 \text { to } 165.8)\end{array}$ \\
\hline Year of highest value & $\begin{array}{l}1985 \\
(1980 \text { to } 1985)\end{array}$ & $\begin{array}{l}1981 \\
\text { (1980 to } 1985)\end{array}$ & $\begin{array}{l}2000 \\
\text { (1999 to 2005) }\end{array}$ & $\begin{array}{l}1986 \\
\text { (1980 to } 1998)\end{array}$ & $\begin{array}{l}2002 \\
(1999 \text { to } 2005)\end{array}$ \\
\hline
\end{tabular}

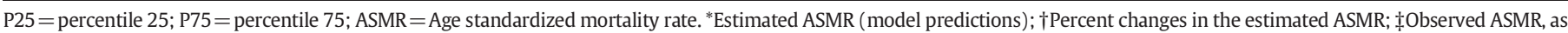
obtained from the World Health Organization database.

upheaval in 1991 with the collapse of the Soviet Union was characterized by the absence of sustained health monitoring and policies, with high levels of tobacco and alcohol consumption and psychosocial stress due to economic and social instability and could justify the increases observed on IHD ASMR in the early 1990s [46-48].

\section{Study limitations}

Miscoding and classification changes in WHO mortality data could explain some of the variation over time and between countries. However, the adoption of three different revisions of ICD across the period considered is not expected to compromise the comparability of data within or between countries $[29,30]$, since the comparability ratios across ICDs are close to 1 for IHD [31,32]. Still, there are issues of completeness of death certification and data validity that may have varied across settings and calendar periods, especially in BRICS and some of the middleincome countries included in our analysis. The data used in our study might have underestimated the true rates in the settings in which the number of deaths refers only to part of the population, particularly when the mortality rates were computed using the UN estimates for the overall population for each country. Nevertheless, this is not expected to compromise the comparison of the rates over time. On the other hand, there are also concerns regarding external validity; in the Republic of Moldova, Russian Federation and Serbia some geographical regions were excluded from the official mortality statistics, and the trends presented may not apply equally to the whole country. This applies to an even larger extent to China, since mortality data covers less than $10 \%$ of the entire population; despite the possible inappropriateness of the generalization to the rest of the country, these data are the best available for this setting, and still useful.

In conclusion, we propose a framework to define clusters of countries with similar patterns of variation in IHD mortality, and a new general model for the description, interpretation and prediction of its trends worldwide.

\section{Appendix A. Supplementary data}

Supplementary data to this article can be found online at http://dx. doi.org/10.1016/j.ijcard.2013.11.004.

\section{References}

[1] World Health Organization. Global Atlas on cardiovascular disease prevention and control. Geneva, Switzerland: World Health Organization; 2011.

[2] World Health Organization. Causes of death 2008. Geneva, Switzerland: World Health Organization; 2008.

[3] Evans A, Tolonen H, Hense H, Ferrario M, Sans S, Kuulasmaa Kl. WHO MONICA Project. Trends in coronary risk factors in the WHO MONICA project. Int J Epidemiol 2001;30:35-40.

[4] Capewell S, Ford E, Croft J, Critchley J, Greenlund K, Labarthe D. Cardiovascular risk factor trends and potential for reducing coronary heart disease mortality in the United States of America. Bull World Health Organ 2010;88:120-30. 
[5] Strong K, Guthold R, Yang J, Lee D, Petit P, Fitzpatrick C. Tobacco use in the European region. Eur J Cancer Prev 2008;17:162-8.

[6] World Health Organization. Gender, women, and the tobacco epidemic. Manila, Philippine: World Health Organization; 2010.

[7] Bennett K, Kabir Z, Capewell S, et al. Explaining the recent decrease in coronary heart disease mortality rates in Ireland, 1985-2000. J Epidemiol Community Health 2006;60:322-7.

[8] Huffman MD, Capewell S, Ning H, Shay CM, Ford ES, Lloyd-Jones DM. Cardiovascular health behavior and health factor changes (1988-2008) and projections to 2020/ clinical perspective. Circulation 2012;125:2595-602.

[9] Danaei G, Finucane MM, Ezzati M, et al. National, regional, and global trends in systolic blood pressure since 1980: systematic analysis of health examination surveys and epidemiological studies with 786 country-years and 54 million participants. Lancet 2011;377:568-77.

[10] Kuulasmaa K, Tunstall-Pedoe H, Ferrario M, et al. Estimation of contribution of changes in classic risk factors to trends in coronary-event rates across the WHO MONICA Project populations. Lancet 2000;355:675-87.

[11] Farzadfar F, Finucane MM, Ezzati M, et al. National, regional, and global trends in serum total cholesterol since 1980: systematic analysis of health examination surveys and epidemiological studies with 321 country-years and 30 million participants. Lancet 2011;377:578-86.

[12] Vartiainen E, Puska P, Pekkanen J, Tuomilehto J, Jousilahti P. Changes in risk factors explain changes in mortality from ischaemic heart disease in Finland. BMJ 1994;309:23-7.

[13] Tolonen H, Mähönen M, Tuomilehto J, et al. Do trends in population levels of blood pressure and other cardiovascular risk factors explain trends in stroke event rates? Comparisons of 15 populations in 9 countries within the WHO MONICA Stroke Project. World Health Organization Monitoring of Trends and Determinants in Cardiovascular Disease. Stroke 2002:33:2367-75.

[14] Wijeysundera H, Machado M, Capewell S, et al. Association of temporal trends in risk factors and treatment uptake with coronary heart disease mortality, 1994-2005. JAMA 2010;303:1841-7.

[15] Martiniuk A, Lee C, Woodward M, et al. Hypertension: its prevalence and population-attributable fraction for mortality from cardiovascular disease in the Asia-Pacific region. J Hypertens 2007;25:73-9.

[16] Mandelzweig L, Battler A, Behar S, et al. The second Euro Heart Survey on acute coronary syndromes: characteristics, treatment, and outcome of patients with ACS in Europe and the Mediterranean Basin in 2004. Eur Heart J 2006;27:2285-93.

[17] Capewell S, Morrison C, McMurray J. Contribution of modern cardiovascular treatment and risk factor changes to the decline in coronary heart disease mortality in Scotland between 1975 and 1994. Heart 1999;81:380-6.

[18] Ford E, Ajani U, Capewell S. Explaining the decrease in U.S. deaths from coronary disease, 1980-2000. N Engl J Med 2007;356:2388-98.

[19] Bertuccio PLF, Lucchini F, Chatenoud L, Bosetti C, Negri E, La Vecchia C. Coronary heart disease and cerebrovascular disease mortality in young adults: recent trends in Europe. Eur J Prev Cardiol 2011;18:627-34.

[20] Levi F, Negri E, La Vecchia C. Trends in mortality from cardiovascular and cerebrovascular diseases in Europe and other areas of the world. Heart 2002;88:119-24.

[21] United Nations. World population prospects, the 2010 revision. http://esa.un.org/ unpd/wpp/index.htm; 2010. [20 January 2012].

[22] World Health Organization Statistical Information System. WHO mortality database. http://www.who.int/whosis/mort/download/en/index.html; 2011. [20 January 2012].

[23] World Health Organization. International classification of disease: 8th revision. Geneva, Switzerland: World Health Organization; 1967.

[24] World Health Organization. International classification of disease: 9th revision. Geneva, Switzerland: World Health Organization; 1977.

[25] World Health Organization. International statistical classification of disease and related health problems: 10th revision. Geneva, Switzerland: World Health Organization; 1992.
[26] Doll R, Smith P. Comparison between registries: age-standardized rates. In: Waterhouse J, Muir C, Shanmugaratnam K, Powell J, Peacham D, Whelan S, editors. Cancer incidence in five continents, Vol IV IARC Scientific Publication No 42Lyon: International Agency for Research on Cancer; 1982. p. 671-5.

[27] Efron B, Tibshirani R. Improvements on cross-validation: The .632 + bootstrap method. J Am Stat Assoc 1997;92:548-60.

[28] The world bank: world development indicators. http://data.worldbank.org/ indicator/NY.GDP.PCAP.CD; January 202012.

[29] Santo A. Equivalence between revisions of the International Classification of Diseases: causes of death. Rev Saude Publica 2000;34:21-8.

[30] Lozano R, Murray C, Lopez A, Satoh T. Miscoding and misclassification of ischaemic heart disease mortality. Global programme on evidence for health policy working. World Health Organization; 2011.

[31] Statistics Canada. Comparability of ICD-10 and ICD-9 for mortality statistics in Canada. http://www.statcan.gc.ca/; January 202012.

[32] Brocco S, Vercellino P, Garrone E, et al. «Bridge Coding» ICD-9, ICD-10 and effects on mortality statistics. Epidemiol Prev 2010;34:109-19.

[33] Critchley JA, Capewell S. Why model coronary heart disease? Eur Heart J 2002;23:110-6

[34] Aspelund T, Gudnason V, Capewell S, et al. Analysing the large decline in coronary heart disease mortality in the Icelandic population aged 25-74 between the years 1981 and 2006. PLOS ONE 2010:5:13957.

[35] Laatikainen T, Critchley J, Vartiainen E, Salomaa V, Ketonen M, Capewell S Explaining the decline in coronary heart disease mortality in Finland between 1982 and 1997. Am J Epidemiol 2005;162:764-73.

[36] Unal B, Critchley J, Capewell S. Explaining the decline in coronary heart disease mortality in England and Wales between 1981 and 2000. Circulation 2004;109:1101-7.

[37] Capewell S, Beaglehole R, Seddon M, McMurray J. Explanation for the decline in coronary heart disease mortality rates in Auckland, New Zealand, between 1982 and 1993. Circulation 2000;102:1511-6.

[38] Björck L, Rosengren A, Bennett K, Lappas G, Capewell S. Modelling the decreasing coronary heart disease mortality in Sweden between 1986 and 2002. Eur Heart J 2009;30:1046-56.

[39] Flores-Mateo G, Grau M, Capewell S, et al. Analyzing the coronary heart disease mortality decline in a Mediterranean population: Spain 1988-2005. Rev Esp Cardiol 2011:64:988-96.

[40] Palmieri L, Bennett K, Giampaoli S, Capewell S. Explaining the decrease in coronary heart disease mortality in Italy between 1980 and 2000. Am J Public Health 2010;100:684-92.

[41] Ërglis A, Dzērve V, Rozenbergs A, et al. A population-based cross-sectional study of cardiovascular risk factor in Latvia. Medicina (Kaunas) 2012;48:3010-316.

[42] Zaborskis A, Sumskas L, Maser M, Pudule I. Trends in drinking habits among adolescents in the Baltic countries over the period of transition: HBSC survey results, 1993-2002. BMC Public Health 2006;6:67.

[43] Reklaitiene R, Tamosiunas A, Virviciute D, Baceviciene M, Luksiene D. Trends in prevalence, awareness, treatment, and control of hypertension, and the risk of mortality among middle-aged Lithuanian urban population in 1983-2009. BMC Cardiovasc Disord 2012;12:68.

[44] Capewell S, O'Flaherty M. Rapid mortality falls after risk-factor changes in populations. Lancet 2011;378:752-3.

[45] Kesteloot H, Sans S, Kromhout D. Dynamics of cardiovascular and all-cause mortality in Western and Eastern Europe between 1970 and 2000. Eur Heart J 2006;27:107-13.

[46] Gersh B, Sliwa K, Mayosi B, Yusuf S. Novel therapeutic concepts: the epidemic of cardiovascular disease in the developing world: global implications. Eur Heart J 2010;31:642-8.

[47] Razvodovsky YE. Beverage-specific alcohol sale and cardiovascular mortality in Russia. J Environ Public Health 2010;2010:253853.

[48] Zatonski WA, Bhala N. Changing trends of diseases in Eastern Europe: closing the gap. Public Health 2012;126:248-52. 